\title{
Le programme de protection de la diversité ethnolinguistique
}

Jon Landaburu

\section{OpenEdition}

Journals

Édition électronique

URL : https://journals.openedition.org/jsa/11391

DOI : 10.4000/jsa.11391

ISSN : 1957-7842

Éditeur

Société des américanistes

Édition imprimée

Date de publication : 5 juin 2010

Pagination : 253-261

ISSN : 0037-9174

\section{Référence électronique}

Jon Landaburu, «Le programme de protection de la diversité ethnolinguistique », Journal de la Société des américanistes [En ligne], 96-1 | 2010, mis en ligne le 22 octobre 2010, consulté le 02 septembre 2022. URL : http://journals.openedition.org/jsa/11391 ; DOI : https://doi.org/10.4000/jsa.11391 


\title{
CHRONIQUE DU GROUPE D'INFORMATION SUR LES AMÉRINDIENS
}

\author{
COLOMBIE
}

\author{
LE PROGRAMME DE PROTECTION \\ DE LA DIVERSITÉ ETHNOLINGUISTIQUE
}

En 2007, le ministère de la Culture du gouvernement colombien s'est doté d'un " programme de protection de la diversité ethnolinguistique » (PPDE) destiné à construire une politique publique d'appui à l'usage et à la promotion des langues minoritaires. La Colombie est un des pays d'Amérique les plus riches en diversité linguistique puisqu'on y compte, outre l'espagnol et ses variantes régionales bien marquées, 65 langues amérindiennes, 2 créoles et la langue rom - parlée par quelques milliers de Gitans -, soit 68 langues désignées offíciellement comme «natives». L'univers amérindien est spécialement diversifié puisqu'il présente, en termes génétiques, 13 familles linguistiques, 8 langues isolées et, en termes typologiques, une très grande variété de structures et de phénomènes (divers types de langues tonales, langues à harmonie nasale, langues agglutinantes, mais aussi isolantes, flexionnelles ou polysynthétiques, langues ergatives, classificateurs, etc.). En termes démographiques globaux, toutefois, la population qui parle ces langues est très minoritaire puisqu'elle pourrait atteindre 800000 personnes, soit moins de $2 \%$ d'un État de 45 millions d'habitants.

Comme d'autres États en Amérique latine, depuis une trentaine d'années, la Colombie a entrepris d'envisager la diversité ethnique et linguistique comme un atout et non comme une tare. La Constitution politique actuelle (1991) proclame dans son article 10 : " con el castellano, las lenguas y los dialectos de los grupos étnicos son también oficiales en sus territorios. La enseñanza que se imparta en las comunidades con tradiciones lingüisticas propias será bilingüe ». Malgré ce texte et d'autres (Convention 169 de la OIT ratifiée par la Colombie en 1991, Loi générale d'éducation de 1994, Loi générale de culture de 1997), l'attitude des pouvoirs publics envers les langues vernaculaires n'avait pas été sensiblement modifiée. Le programme mis en place au ministère de la Culture travaille sur quatre fronts :

1) campagnes d'opinion tant au niveau national qu'au niveau des peuples locuteurs de langues pour sensibiliser le public à la valeur de la diversité linguistique et à l'intérêt de l'usage de la langue de l'ethnie ; 
2) amélioration de l'offre publique en créant des dispositifs légaux et financiers, nationaux et régionaux, permettant d'appuyer les efforts publics et privés en faveur de la protection et la revitalisation des langues ;

3) enrichissement de l'information sur la situation sociolinguistique des langues (statut) et aide à la progression de la connaissance scientifique des formes linguistiques ;

4) appui et suivi des projets de revitalisation déposés par les usagers (autorités légales des peuples, enseignants, particuliers, etc.).

Ces quatre fronts s'articulent selon le schéma opérationnel suivant : un autodiagnostic sociolinguistique de l'état de vitalité de chaque langue mis en place par chaque groupe ethnolinguistique avec l'aide du programme du ministère de la Culture permet la détection et la construction de projets accordés à chaque situation. L'autodiagnostic effectué par la communauté aide à la valorisation de la langue et à la conscience des éventuels dangers de sa situation. Les programmes et projets issus de cette démarche peuvent se développer grâce à la mise en place d'un nouveau cadre législatif.

Durant les années 2008 et 2009, le programme PPDE a pu effectuer avec les communautés l'autodiagnostic des 15 langues suivantes : chimila, wiwa, palenquero (créole à base lexicale espagnole), cuna, wounan, cofan, ticuna, cubeo, tucano, puinave, curripaco, sikuani, sáliba, paez ou nasa, guambiano. L'autodiagnostic des 15 autres langues suivantes est en cours: wayu, coreguaje, inga, kamëntsá, andoke, bora, miraña, muinane, uitoto, ocaina, nonuya, piaroa, sanandresano (créole à base lexicale anglaise des îles de San Andrés), achagua, piapoco. L'observation de l'état de vitalité de toutes les langues "natives" devrait ainsi être achevé d'ici deux ans.

Le 9 décembre 2009, une loi de protection des langues natives a été votée par le Congrès de la République. Elle a été promulguée le 26 janvier 2010 sous le $\mathrm{n}^{\circ} 1381$. Nous en donnons le texte plus loin. Après le Mexique (Ley general de los derechos lingüísticos de los pueblos indigenas, mars 2003), le Guatemala (Ley de idiomas nacionales, mai 2003), le Pérou (Ley de reconocimiento, preservación, fomento y difusión de las lenguas aborígenes, octobre 2003), le Venezuela (Ley de idiomas indigenas, mai 2008), la Colombie s'est donc dotée d'un dispositif législatif favorable. Comme pour toute mesure de politique linguistique, le succès dépend fondamentalement de l'attitude et des aspirations des locuteurs. Dans cette lutte, la Colombie dispose de plusieurs atouts : l'existence de mouvements sociaux indiens particulièrement forts et combatifs et la vitalité préservée de nombreuses de ces langues. Les autodiagnostics nous ont ainsi donné des indices de pratique de la langue souvent très élevés : de 75 à $90 \%$ pour les Cuna, Wounan, Curripaco, Puinave, Sikuani, Cubeo, etc. Ces chiffres ne sauraient toutefois faire oublier que la menace est considérable, que 5 langues sont actuellement en train de disparaître, qu'au moins 20 langues 
sont sérieusement en danger et que, des 65 langues indiennes, la moitié sont parlées par moins de 1000 locuteurs.

Jon LANDABURU

Directeur du « Programa de Protección de la Diversidad Etnolingüística », ministère de la Culture de Colombie

\section{LEY NUMERO 1381 - 25 Enero 2010}

por la cual se desarrollan los artículos $7^{\circ}, 8^{\circ}, 10$ y 70 de la Constitución Politica, y los articulos $4^{\circ}, 5^{\circ}$ y 28 de la Ley 21 de 1991 (que aprueba el Convenio 169 de la OIT sobre pueblos indigenas y tribales), y se dictan normas sobre reconocimiento, fomento, protección, uso, preservación y fortalecimiento de las lenguas de los grupos étnicos de Colombia y sobre sus derechos lingüisticos y los de sus hablantes.

\section{El Congreso de la República de Colombia DECRETA: \\ TÍTULO I \\ PRINCIPIOS Y DEFINICIONES}

Artículo $1^{\circ}$. Naturaleza y objeto. La presente ley es de interés público y social, y tiene como objeto garantizar el reconocimiento, la protección y el desarrollo de los derechos lingüísticos, individuales y colectivos de los grupos étnicos con tradición lingüística propia, así como la promoción del uso y desarrollo de sus lenguas que se llamarán de aquí en adelante lenguas nativas.

Se entiende por lenguas nativas las actualmente en uso habladas por los grupos étnicos del país, así: las de origen indoamericano, habladas por los pueblos indígenas, las lenguas criollas habladas por comunidades afrodescendientes y la lengua Romaní hablada por las comunidades del pueblo rom o gitano y la lengua hablada por la comunidad raizal del Archipiélago de San Andrés, Providencia y Santa Catalina.

Artículo $2^{\circ}$. Preservación, salvaguarda y fortalecimiento de las lenguas nativas. Las lenguas nativas de Colombia constituyen parte integrante del patrimonio cultural inmaterial de los pueblos que las hablan, y demandan por lo tanto una atención particular del Estado y de los poderes públicos para su protección y fortalecimiento.

La pluralidad y variedad de lenguas es una expresión destacada de la diversidad cultural y étnica de Colombia y en aras de reafirmar y promover la existencia de una Nación multiétnica y pluricultural, el Estado, a través de los distintos organismos de la administración central que cumplan funciones relacionadas con la materia de las lenguas nativas o de los grupos étnicos que las hablan, y a través de las Entidades Territoriales, promoverá la preservación, la salvaguarda y el fortalecimiento de las lenguas nativas, mediante la adopción, financiación y realización de programas especificos.

Artículo $3^{\circ}$. Principio de concertación. En la interpretación y aplicación de las disposiciones de la presente ley, las entidades del Estado investidas de atribuciones para el cumplimiento de funciones relacionadas con las lenguas nativas, deberán actuar con 
reconocimiento y sujeción a los principios de la necesaria concertación de sus actividades con las comunidades de los grupos étnicos y sus autoridades, y de autonomía de gobierno interno del que gozan estas poblaciones en el marco de las normas constitucionales y de los convenios internacionales ratificados por el Estado.

\section{TÍTULO II \\ DERECHOS DE LOS HABLANTES DE LENGUAS NATIVAS}

Artículo $4^{\circ}$. No discriminación. Ningún hablante de una lengua nativa podrá ser sometido a discriminación de ninguna índole, a causa del uso, transmisión o enseñanza de su lengua.

Artículo $5^{\circ}$. Derecho de uso de las lenguas nativas y del castellano. Los hablantes de lengua nativa tendrán derecho a comunicarse entre sí en sus lenguas, sin restricciones en el ámbito público o privado, en todo el territorio nacional, en forma oral o escrita, en todas sus actividades sociales, económicas, políticas, culturales y religiosas, entre otras. Todos los habitantes de los territorios de los pueblos indígenas, del corregimiento de San Basilio de Palenque (municipio de Mahates, departamento de Bolívar), y del departamento de San Andrés y Providencia, tendrán el derecho a conocer y a usar las lenguas nativas de uso tradicional en estos territorios, junto con el castellano. A las comunidades del pueblo rom, se les garantizará el derecho a usar el castellano y la lengua Romaní de uso tradicional en dichas comunidades.

Artículo $6^{\circ}$. Nombres propios y toponimia en las lenguas nativas. Los nombres y apellidos de personas provenientes de la lengua y de la tradición cultural usados por los hablantes de lenguas nativas, y más generalmente por los integrantes de pueblos y comunidades donde se hablen estas lenguas, podrán ser reconocidos para efectos públicos. Este uso será registrado por la autoridad oficial competente previa solicitud de los interesados.

Igualmente los nombres de lugares geográficos usados tradicionalmente en su territorio por los integrantes de pueblos y comunidades donde se hablen lenguas nativas podrán ser registrados para efectos públicos. Este uso será cooficial con la toponimia en castellano cuando esta exista. La transcripción alfabética de estos nombres propios y de esta toponimia será reglamentada por el Consejo Nacional Asesor de Lenguas Nativas previsto en el artículo 24 de la presente ley.

Artículo $7^{\circ}$. Derechos en las relaciones con la justicia. Los hablantes de lenguas nativas que por razones jurídicas de cualquier índole, tengan que comparecer ante los órganos del Sistema Judicial Nacional, tendrán derecho a actuar en su propia lengua, y las autoridades responsables proveerán lo necesario para que, en los juicios que se realicen, quienes lo solicitaren sean asistidos gratuitamente por intérpretes y defensores que tengan conocimiento de su lengua y cultura. El Ministerio del Interior y de Justicia acordará con las autoridades de los departamentos, distritos, municipios y con las autoridades de los grupos étnicos donde habiten comunidades que hablen lenguas nativas, la adopción de medidas que permitan avanzar progresivamente en el cumplimiento y satisfacción de los derechos y compromisos definidos en el presente artículo.

Artículo $8^{\circ}$. Derechos en las relaciones con la administración pública. Los hablantes de lenguas nativas tienen el derecho al empleo de su propia lengua en sus actuaciones 
y gestiones ante los órganos de la administración pública. Las autoridades competentes del orden Nacional, Departamental, Distrital y Municipal proveerán lo necesario para que quienes lo demanden sean asistidos gratuitamente por intérpretes que tengan conocimiento de su lengua y cultura. Las entidades competentes del orden Nacional, Departamental, Distrital y Municipal, acordarán la adopción de medidas que permitan avanzar progresivamente en el cumplimiento y satisfacción de los derechos y compromisos definidos en el presente artículo. Así mismo asegurarán la difusión, a través de textos impresos, documentos de audio, audiovisuales y otros medios disponibles, de las leyes y reglamentos así como de los contenidos de los programas, obras y servicios dirigidos a los grupos étnicos, en la lengua de sus correspondientes beneficiarios para su debida información.

Artículo $9^{\circ}$. Derechos en las relaciones con la salud. En sus gestiones y diligencias ante los servicios de salud, los hablantes de lenguas nativas tendrán el derecho de hacer uso de su propia lengua y será de incumbencia de tales servicios, la responsabilidad de proveer lo necesario para que los hablantes de lenguas nativas que lo solicitaran, sean asistidos gratuitamente por intérpretes que tengan conocimiento de su lengua y cultura. El Ministerio de la Protección Social y las Secretarías Departamentales y Municipales de Salud, acordarán con las entidades aseguradoras y prestadoras de los servicios del ramo, públicas y privadas, las medidas apropiadas que permitan avanzar progresivamente en el cumplimiento y satisfacción de los derechos y compromisos definidos en el presente artículo.

\section{TÍTULO III \\ PROTECCIÓN DE LAS LENGUAS NATIVAS}

Artículo 10. Programas de fortalecimiento de lenguas nativas. EI Plan Nacional de Desarrollo y los Planes de Desarrollo de las Entidades Territoriales, en concertación con las autoridades de los grupos étnicos, incluirán programas y asignarán recursos para la protección y el fortalecimiento de las lenguas nativas. El Ministerio de Cultura será el encargado de coordinar el seguimiento, la ejecución y la evaluación de estos programas de acuerdo con el Principio de Concertación previsto en el artículo $3^{\circ}$ de la presente ley.

Artículo 11. Protección y salvaguardia de las lenguas nativas. Todas las lenguas nativas existentes en el país, a partir de la vigencia de la presente ley, quedan incorporadas a la Lista Representativa de Manifestaciones de Patrimonio Cultural Inmaterial prevista en la Ley 1185 de 2008 sin previo cumplimiento del procedimiento previsto en el inciso $2^{\circ}$ del literal b) del artículo $4^{\circ}$ de la Ley 397 de 1997 modificado por la Ley 1185 de 2008. Las lenguas nativas quedan por consiguiente amparadas por el Régimen Especial de Protección y de Salvaguardia reconocido por dicho ordenamiento.

Artículo 12. Lenguas en peligro de extinción. El Ministerio de Cultura y las Entidades Territoriales, después de consultar y concertar con las comunidades correspondientes, coordinarán el diseño y la realización de planes de urgencia para acopiar toda la documentación posible sobre cada una de las lenguas nativas en peligro de extinción y para desarrollar acciones orientadas a conseguir en lo posible su revitalización. El Consejo Nacional Asesor previsto en el artículo 24 de la presente ley determinará la lista de las lenguas que se encuentren en esta condición. 
Artículo 13. Lenguas en estado de precariedad. El Ministerio de Cultura y las entidades territoriales concertarán con las autoridades de los pueblos y comunidades correspondientes el diseño y la realización de programas de revitalización y fortalecimiento de lenguas nativas en estado de precariedad. El Consejo Nacional Asesor previsto en el artículo 24 determinará la lista de las lenguas que se encuentren en esta condición.

Artículo 14. Reivindicación de lenguas extintas. Los pueblos y comunidades que manifiesten interés por la recuperación de su lengua cuyo uso perdieron de tiempo atrás, y que inicien procesos endógenos de recuperación de formas lingüísticas pertenecientes a dicha lengua, podrán recibir el apoyo del Estado, si se dan condiciones de viabilidad y de compromiso colectivo para dicha recuperación.

Artículo 15. Pueblos fronterizos. En el marco de acuerdos o convenios binacionales con las naciones vecinas al país, en cuyos territorios fronterizos con Colombia existan comunidades y pueblos que hablen la misma lengua nativa de los dos lados de la frontera, el Estado, a través del Ministerio de Cultura y del Ministerio de Relaciones Exteriores, y en concertación con las autoridades de los pueblos aludidos, diseñará planes conjuntos de protección y fortalecimiento de las lenguas compartidas.

Artículo 16. Medios de comunicación. En desarrollo de lo señalado en el parágrafo $2^{\circ} \mathrm{del}$ artículo 20 de la Ley 335 de 1996, el Estado adoptará medidas y realizará las gestiones necesarias para la difusión de la realidad y el valor de la diversidad lingüística y cultural de la Nación en los medios de comunicación públicos. Así mismo, y en concertación con las autoridades de los grupos étnicos, impulsará la producción y emisión de programas en lenguas nativas en los distintos medios tecnológicos de información y comunicación como estrategia para la salvaguardia de las lenguas nativas. El Ministerio de Cultura, el Ministerio de Tecnología de la Información y las Comunicaciones, la Comisión Nacional de Televisión, los departamentos, los distritos y los municipios con comunidades que hablen lenguas nativas, prestarán su apoyo a la realización de dichos programas.

Artículo 17. Producción de materiales de lectura. El Estado, a través del Ministerio de Cultura, del Ministerio de Educación Nacional, de las Secretarías de Educación de las Universidades Públicas y de otras entidades públicas o privadas que tengan capacidad y disposición para ello, en estrecha concertación con los pueblos y comunidades de los grupos étnicos y sus autoridades, impulsará iniciativas y aportará recursos destinados a la producción y uso de materiales escritos en las lenguas nativas. En el cumplimiento de los esfuerzos que desarrollen esta disposición, se otorgará preferencia a la publicación de materiales que tengan relación con los valores culturales y tradiciones de los pueblos y comunidades étnicas del país, elaborados por sus integrantes.

Artículo 18. Producción de materiales de audio, audiovisuales y digitales. El Estado, a través del Ministerio de Cultura y de otras entidades públicas o privadas, en estrecha concertación con los pueblos y comunidades de los grupos étnicos y sus autoridades, impulsará iniciativas y aportará recursos destinados a la producción y uso de materiales de audio, audiovisuales y digitales en las lenguas nativas. Además se fomentará la capacitación para la producción de materiales realizados por integrantes de las mismas comunidades. De la misma manera se facilitará a los hablantes de lenguas nativas el acceso a los nuevos medios tecnológicos y de comunicación utilizando documentos en lenguas nativas y propiciando la creación de portales de Internet para este uso. 
Artículo 19. Conservación y difusión de materiales sobre lenguas nativas. El Ministerio de Cultura, a través del Archivo General de la Nación, Instituto Caro y Cuervo, Instituto Colombiano de Antropología e Historia, la Biblioteca Nacional y demás entidades competentes, impulsará la recolección, conservación y difusión de materiales escritos, de audio y audiovisuales representativos de las lenguas nativas y de las tradiciones orales producidas en estas lenguas, en bibliotecas, hemerotecas, centros culturales y archivos documentales nacionales, regionales, locales y de grupos étnicos.

Artículo 20. Educación. Las autoridades educativas Nacionales, Departamentales, Distritales y Municipales y las de los pueblos y comunidades donde se hablen lenguas nativas, garantizarán que la enseñanza de estas sea obligatoria en las escuelas de dichas comunidades. La intensidad y las modalidades de enseñanza de la lengua o las lenguas nativas frente a la enseñanza del castellano, se determinarán mediante acuerdo entre las autoridades educativas del Estado y las autoridades de las comunidades, en el marco de procesos etnoeducativos, cuando estos estén diseñados.

El Estado adoptará las medidas y realizará las gestiones necesarias para asegurar que en las comunidades donde se hable una lengua nativa los educadores que atiendan todo el ciclo educativo hablen y escriban esta lengua y conozcan la cultura del grupo. El Ministerio de Educación Nacional, en coordinación con las universidades del país y otras entidades idóneas motivará y dará impulso a la creación de programas de formación de docentes para capacitarlos en el buen uso y enseñanza de las lenguas nativas. El Ministerio de Cultura, como entidad del Estado responsable de impulsar la defensa y vigorización de las lenguas nativas, el Ministerio de Educación y las Secretarías de Educación realizarán convenios de mutuo apoyo y cooperación para todo lo concerniente a la enseñanza y aprovechamiento de las lenguas nativas en los programas educativos de los grupos étnicos.

Parágrafo. Para la atención de la población en edad escolar objeto de esta ley, podrán ingresar al servicio educativo personal auxiliar en lengua nativa, siempre y cuando se demuestre la necesidad de garantizar la adecuada prestación de dicho servicio. El ingreso se hará mediante un proceso de designación comunitaria el cual será reglamentado por el Ministerio de Educación Nacional.

Artículo 21. Programas de investigación y de formación. El Departamento Administrativo de Ciencia, Tecnología e Innovaciones-Colciencias como entidad rectora del Sistema Nacional de Ciencia, Tecnología e Innovación apoyará proyectos de investigación y de documentación sobre lenguas nativas, y velará para que el resultado sea conocido por las comunidades donde se haya desarrollado. Dichos proyectos deberán ser consultados ante las autoridades de los grupos étnicos donde se desarrollen. El Estado también prestará su apoyo a instituciones públicas y privadas que tengan la idoneidad necesaria para implementar programas de formación de investigadores en lenguas nativas. Se dará un especial apoyo a la formación de investigadores seleccionados entre los integrantes de las comunidades nativas.

Con el fin de atender los requerimientos descritos en los artículos $7^{\circ}, 8^{\circ}$ y $9^{\circ}$ del Título II de la presente ley, el Ministerio de Cultura coordinará con el Ministerio de Educación Nacional y con otras instituciones del Estado, la creación de programas de formación de traductores-intérpretes en lenguas nativas y castellano, implementados por las instituciones públicas y privadas que tengan la idoneidad necesaria. 
El Estado prestará su apoyo a universidades y otras entidades educativas idóneas para crear cátedras para el estudio y aprendizaje de lenguas nativas. También estimulará la creación de programas de capacitación en el conocimiento y uso de lenguas de comunidades nativas, dirigidos a aquellas personas no indígenas que tienen la responsabilidad en la prestación de servicios públicos o desarrollo de programas a favor de aquellas comunidades de grupos étnicos que enfrentan dificultades para comunicarse en castellano.

Parágrafo. Los proyectos sobre lenguas nativas a que se refiere este artículo, serán financiados o cofinanciados con los recursos que para investigación destine el Ministerio de Cultura.

Artículo 22. Observación de la situación de las lenguas nativas. El Estado adelantará cada cinco años una encuesta sociolingüística que permita realizar una observación sistemática de las prácticas lingüísticas y evaluar la situación de uso de las lenguas nativas de Colombia. Esta encuesta sociolingüística contará con la asesoría del Ministerio de Cultura y se ejecutará en concertación con las autoridades de los pueblos y comunidades de los grupos étnicos.

\section{TÍTULO IV \\ GESTIÓN DE LA PROTECCIÓN DE LAS LENGUAS NATIVAS}

Artículo 23. El Ministerio de Cultura y las lenguas nativas. El Ministerio de Cultura coordinará la acción del Estado para la formulación y la puesta en aplicación de la política de protección y fortalecimiento de las lenguas nativas de las que se ocupa esta ley. Para la definición y puesta en ejecución de una política coherente, sostenible e integral de protección y fortalecimiento de las lenguas nativas, el Ministerio de Cultura, tendrá las siguientes funciones:

a) Formular en concertación con las comunidades donde se hablen lenguas nativas una política de protección y fortalecimiento de estas lenguas.

b) Ayudar en el diseño, apoyar la implementación y evaluar los programas de protección de lenguas nativas definidos en el marco de esta ley.

c) Asesorar a las entidades de carácter nacional, territorial y de grupos étnicos que ejecuten programas de protección de lenguas nativas definidos en el marco de esta ley. d) Preparar un Plan Nacional Decenal de Protección y Fortalecimiento de las Lenguas Nativas teniendo en cuenta los objetivos definidos en esta ley y coordinar el desarrollo de sus acciones.

e) Presentar y concertar el Plan Nacional Decenal de Protección y Fortalecimiento de las Lenguas Nativas en la Mesa Nacional de Concertación de pueblos indígenas y en la Consultiva de Alto Nivel de las Comunidades Negras.

f) Articular con las Entidades Territoriales pertinentes el desarrollo de actividades a favor de las lenguas nativas.

g) Gestionar a nivel Nacional e Internacional recursos científicos, técnicos o financieros para promover programas y proyectos a favor de las lenguas nativas.

h) Ejercer las funciones de la secretaría ejecutiva del ¿Consejo Nacional Asesor de Lenguas Nativas? definido en el artículo 24 de la presente ley. 
Artículo 24. Consejo Nacional Asesor de Lenguas Nativas. Créase el Consejo Nacioal Asesor de Lenguas Nativas, como organismo técnico encargado de asesorar al Ministerio de Cultura en la definición, adopción y orientación de los planes de protección y fortalecimiento de las lenguas de grupos étnicos presentes en el territorio nacional. Este Consejo estará conformado mayoritariamente por personas pertenecientes a los grupos étnicos hablantes sabedores reconocidos de sus lenguas y/o con trayectoria en su promoción, los cuales serán elegidos por la misma comunidad, de acuerdo con la reglamentación concertada entre el Ministerio y voceros de las comunidades. También contará con la presencia de un experto en lenguas nativas del Instituto Caro y Cuervo, de un experto en lenguas nativas de la Universidad Nacional de Colombia, de un experto en representación de las otras universidades que desarrollan programas de investigación en lenguas nativas y de un experto en representación de las universidades que desarrollan programas de etnoeducación. Así mismo contará con la presencia de un delegado del Ministro de Educación Nacional con responsabilidades en el tema de la educación entre grupos étnicos y de un delegado del Ministerio de Tecnología de la Información y las Comunicaciones, responsable del tema de medios de comunicación dentro de los grupos étnicos. El Ministerio de Cultura reglamentará la composición, las funciones y el funcionamiento del Consejo Nacional Asesor de Lenguas Nativas y asignará los recursos necesarios para su funcionamiento.

Articulo 25. Día Nacional de las lenguas nativas. Declarase el 21 de febrero de cada año como día nacional de las lenguas nativas. Anualmente en esta fecha se realzará y promoverá el valor de la pluralidad lingüística y la diversidad cultural mediante la realización de actos y programas educativos a nivel nacional, en coordinación con las actividades propias del día internacional de la lengua materna.

\section{Artículos transitorios}

Artículo transitorio $1^{\circ}$. Consejo Nacional Asesor de Lenguas Nativas. La reglamentación del Consejo Nacional Asesor de Lenguas Nativas prevista en el artículo 24, deberá entrar a regir en un plazo no mayor a un año contado a partir de la fecha de promulgación de la presente ley.

Artículo transitorio $2^{\circ}$. Plan Decenal. El Plan Decenal de acción a favor de las lenguas nativas previsto en el artículo 23 será preparado por el Ministerio de Cultura con la asesoría del Consejo Nacional Asesor de Lenguas Nativas y concertado con las comunidades de los grupos étnicos y sus autoridades en un plazo no mayor a dos años contados a partir de la fecha de promulgación de la presente ley.

Artículo transitorio $3^{\circ}$. Encuesta sociolingüística. La encuesta sociolingüística o de autodiagnóstico actualmente promovida por el Ministerio de Cultura para determinar el estado y uso actuales de las lenguas nativas, deberá ser concluido para todas las lenguas nativas de Colombia en un plazo no mayor de dos años, contados a partir de la promulgación de la presente ley.

Artículo 26. Vigencia y derogatorias. Esta ley rige a partir de su promulgación y deroga todas las disposiciones que le sean contrarias. 